\title{
Orléans - 9-13 quai du Roi
}

$\mathrm{n}^{\circ} 064518$

\section{Simon Bryant}

\section{(2) OpenEdition}

\section{Journals}

Édition électronique

URL : http://journals.openedition.org/adlfi/14326

ISSN : 2114-0502

Éditeur

Ministère de la culture

Référence électronique

Simon Bryant, «Orléans - 9-13 quai du Roi », ADLFI. Archéologie de la France - Informations [En ligne] Centre, mis en ligne le 20 mars 2015, consulté le 01 mai 2019. URL : http://journals.openedition.org/ adlfi/14326

Ce document a été généré automatiquement le 1 mai 2019.

(C) Ministère de la Culture et de la Communication, CNRS 


\title{
Orléans - 9-13 quai du Roi
}

\author{
$n^{\circ} 064518$
}

\section{Simon Bryant}

Lien Atlas (MCC) :

http://atlas.patrimoines.culture.fr/atlas/trunk/index.php?

ap_theme=DOM_2.01.02\&ap_bbox=1.874;47.813;1.949;47.933

1 La zone concernée par cette étude est définie par la rue de l'Abreuvoir à l'ouest, la rue Croix Péchée au nord, la rue Charles Péguy à l'est et le quai du Roi au sud. Elle couvre une superficie totale de $3200 \mathrm{~m}^{2}$.

2 Cette intervention, au mois d'août 1998, fait suite à l'évaluation réalisée en 1997. Le site, situé à l'ouest de la ville antique, représente les abords de l'ancien théâtre gallo-romain. Celui-ci, situé sous les parcelles à l'ouest de la rue de l'Abreuvoir, a été démoli pour récupérer les blocs de pierre lors de la construction du quai au XIX ${ }^{\mathrm{e}}$ s. L'opération de 1997 a mis au jour une partie du pavage du quai, composé des éléments architectoniques de l'édifice antique (corniches, dalles de sol, etc).

3 Seule une bande de $20 \mathrm{~m}^{2}$ a été conservée, contenant 122 pierres en plus des 79 observées lors de la fouille de 1997. Leur étude a montré une prédominance de dalles de sol de 30 à $36 \mathrm{~cm}$ de côté, réalisées en calcaire cristallin. Les dimensions correspondent aux modules antiques de 1 pied de côté (1') avec quelques exemples d'un module de 1' sur 1'6". Un petit nombre de grands blocs de calcaire blanc, de $45 \mathrm{~cm}$ sur $90 \mathrm{~cm}$ a également été observé (module de 1'6" sur 3'). Leur fonction reste inconnue mais ils pourraient représenter des blocs des gradins ou des dalles de sol. Finalement, une vingtaine de dalles plates, réalisées en une roche noire et siliceuse, représente la troisième catégorie de blocs.

4 L'origine des pierres a pu être déterminée. Les dalles de calcaire proviennent des carrières de la Beauce et la diversité apparente (7 catégories observées) est illusoire : il peut s'agir simplement de différents faciès d'un même gisement. Un bloc de calcaire blanc du Nivernais a été noté. Le dernier groupe de revêtement de sol représente des dalles de 
roche volcanique, semblable aux laves utilisées pour les meules. Elles proviennent sans doute de l'Allier.

5 Si l'état de conservation du quai était plutôt décevant, cette opération a permis d'en savoir un peu plus sur la forme et les origines des pierres du théâtre antique. Si les différents faciès du calcaire local sont majoritaires, la présence de roches du Nivernais et $\mathrm{du}$ Massif Central a mis en évidence l'approvisionnement du chantier en pierres d'importation via la Loire.

INDEX

Index géographique : Centre, Loiret (45), Orléans

operation Sauvetage urgent (SU)

Index chronologique : Gallo-romain

Mots-clés : bloc de pierre, dalle 